\title{
Pemanfaatan Limbah Beton Sisa Pengujian Sebagai Substitusi Agregat Pada Campuran AC-WC
}

\author{
Ahmad Maulana ${ }^{1}$, Megah Amaliah ${ }^{2}$, Retno Utami $^{3}$ \\ 1,2,3 Jurusan Teknik Sipil Politeknik Negeri Bandung \\ E-mail: retnoutami@polban.ac.id
}

\begin{abstract}
ABSTRAK
Keterbatasan sumber daya alam dalam menyediakan material membentuk beton merupakan sebuah persoalan yang penting. Oleh karena itu, lebih baik dimanfaatkan sebagai campuran aspal AC-WC seperti limbah beton pengujian praktik di POLBAN. Penelitian ini bertujuan untuk mengetahui pengaruh penggunaan limbah beton sebagai pengganti agregat kasar terhadap kinerja karakteristik campuran aspal AC-WC. Material limbah beton yang digunakan adalah agregat kasar ukuran 12,5 mm dan 9,5 mm dan kadar limbah beton yang digunakan dalam campuran yaitu 0\%, 50\%, dan 100\%. Tujuan dibuat 3 jenis campuran dengan kadar yang berbeda adalah agar didapatkan pengaruh limbah beton dan kadar limbah beton optimum yang dapat digunakan sebagai substitusi agregat kasar pada campuran aspal AC-WC. Metodologi campuran yang digunakan adalah dengan metode kepadatan mutlak sampai mendapatkan kadar aspal optimum. Hasil dari penelitian ini adalah dengan kadar limbah $50 \%$ nilai stabilitas naik $18,34 \%$, nilai flow turun $45,43 \%$, nilai stabilitas sisa turun $20,75 \%$, nilai VIM naik $14,78 \%$, nilai VMA naik $18,26 \%$, dan nilai VFB turun $0,90 \%$. Sedangkan dengan kadar limbah $100 \%$ nilai stabilitas naik 18,62\%, nilai flow turun 47,21\%, nilai stabilitas sisa turun 30,19\%, nilai VIM naik 36,02\%, nilai VMA naik 23,66\%, dan nilai VFB turun 2,09\%. Kadar limbah beton optimum yang dapat digunakan adalah $50 \%$.
\end{abstract}

Kata Kunci: Limbah Beton, Campuran Aspal AC -WC, dan Kadar Substitusi Agregat Kasar

\begin{abstract}
Limited natural resources in providing material to form concrete is an important issue. Therefore, it is better to use it as an ACWC asphalt mixture such as concrete waste testing practices at POLBAN. This study aims to determine the effect of the use of concrete waste as a substitute for coarse aggregate on the performance characteristics of AC-WC asphalt mixtures. Concrete waste materials used are coarse aggregate sizes of $12.5 \mathrm{~mm}$ and $9.5 \mathrm{~mm}$ and concrete waste content used in mixtures are $0 \%$, $50 \%$, and $100 \%$. The purpose of making 3 types of mixtures with different levels is to obtain the effect of concrete waste and optimum levels of concrete waste that can be used as substitute for coarse aggregate on AC-WC asphalt mixture. The mixed methodology used is the absolute density method to obtain optimum asphalt content. The results of this study are 50\% of the waste value stability value increased $18.34 \%$, flow value decreased $45.43 \%$, residual stability value decreased $20.75 \%$, VIM value increased $14.78 \%$, VMA value increased $18.26 \%$, and the VFB value is down $0.90 \%$. Whereas with $100 \%$ waste content, the stability value increased by $18.62 \%$, the flow value decreased by $47.21 \%$, the remaining stability value decreased by $30.19 \%$, the VIM value increased by $36.02 \%$, the VMA value increased by $23.66 \%$, and the VFB value down 2.09\%. The optimum level of concrete waste that can be used is $50 \%$.
\end{abstract}

Keywords: Concrete Waste, Asphalt Mixture AC-WC, and Coarse Aggregate Substitution Levels

\section{PENDAHULUAN}

Keterbatasan sumber daya alam dalam menyediakan material pembentuk beton merupakan sebuah persoalan yang penting. Seperti pembongkaran bangunan dan infrastruktur sipil dengan menggunakan material beton yang menghasilkan limbah. Limbah beton yang dibiarkan tanpa ada penanganan akan menimbulkan permasalahan tersendiri bagi lingkungan. Topik yang akan kami bahas adalah pembuatan campuran aspal menggunakan material agregat yang berasal dari limbah beton. Pemanfaatan tersebut dilakukan karena agregat merupakan bahan tidak terbaharukan dan pengambilannya selalu merusak alam. Seperti misalnya banyak sisa beton pengujian praktik di POLBAN yang tidak terpakai dan hanya menjadi sampah sehingga menghabiskan lahan. Limbah beton bekas pengujian tersebut lebih baik dipakai sebagai campuran aspal AC-WC sebagai bahan substitusi agregat. Pada penelitian ini material limbah beton yang digunakan adalah agregat kasar ukuran 12,5 mm dan 9,5 mm. Kadar limbah beton yang digunakan dalam campuran adalah 0\%, 50\%, dan 100\%. Tujuan dibuat 3 jenis campuran dengan kadar yang berbeda adalah agar didapatkan seperti apa grafik pengaruh limbah beton tersebut terhadap campuran aspal AC-WC.

Sebelum penelitian ini dilakukan, telah banyak dilakukan penelitian mengenai penggunaan limbah beton sebagai material konstruksi. Hasil penelitian sebelumnya adalah nilai kuat tekan CTB limbah beton umur 7 hari memenuhi Spesifikasi Umum Bina Marga Tahun 2010, sedangkan CTB umur 28 hari tidak memenuhi. (Rahman, 2014), nilai kadar limbah beton pada campuran AC-WC gradasi kasar yang optimum adalah sebesar 2,5\% terhadap total agregat kasar. (Andhikatama, 2013 ), dan 
nilai kadar limbah beton pada campuran Hot Roller Sheet Base yang optimum adalah sebesar 10\% terhadap total agregat kasar (Rahmad, 2016).

\section{TUJUAN}

Adapun tujuan dari penelitian ini adalah sebagai berikut.

a. Mengetahui pengaruh penggunaan limbah beton sebagai pengganti agregat kasar ter- hadap kinerja karakteristik campuran aspal AC-WC.

b. Untuk mengetahui kadar limbah beton optimum yang dapat digunakan sebagai substitusi agregat kasar pada campuran aspal AC-WC.

\section{METODOLOGI PENELITIAN}

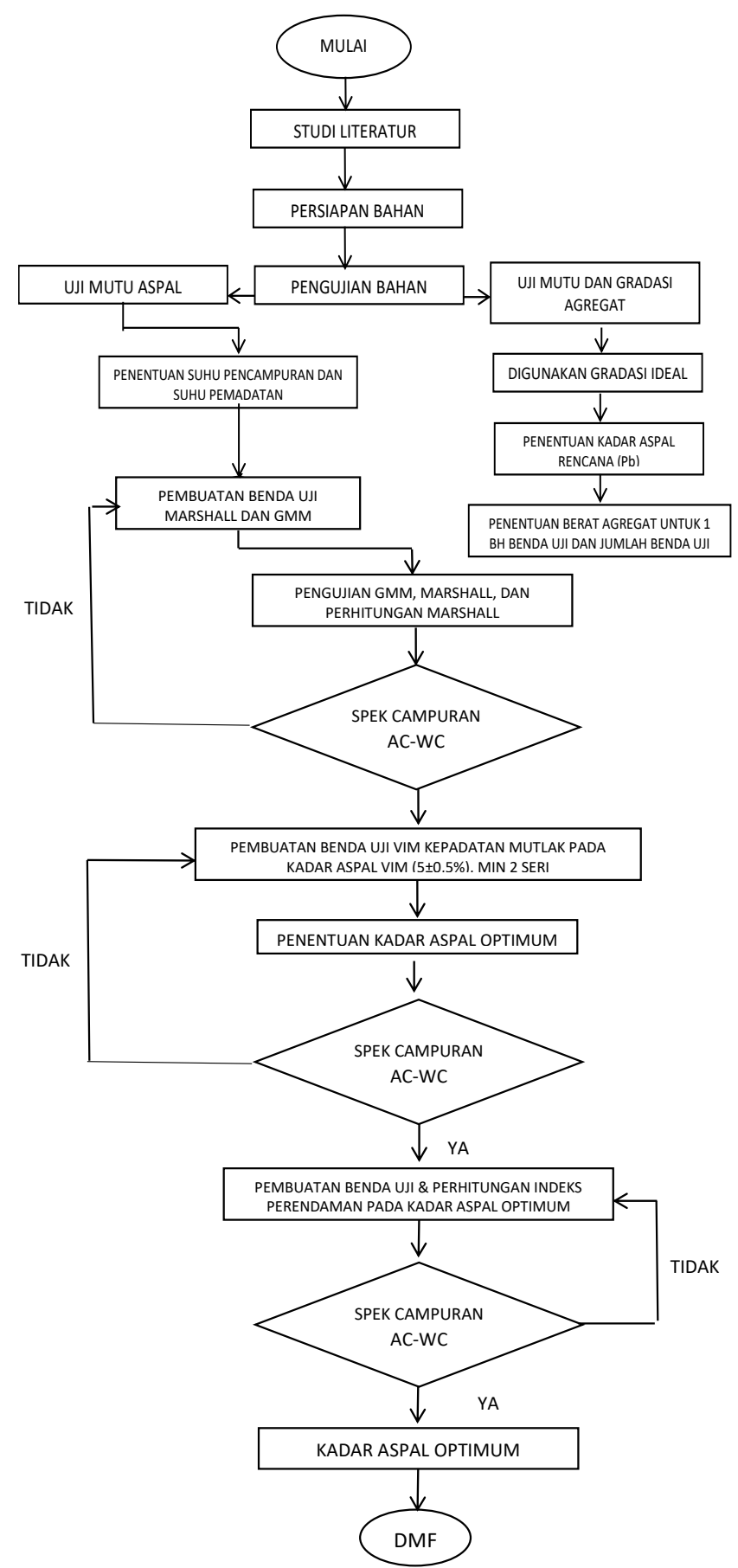

Gambar 1. Diagram Alir Metodologi Penelitian 
Seperti terlihat pada Gambar 1., metodologi campuran yang digunakan adalah dengan metode kepadatan mutlak sampai mendapatkan kadar aspal optimum. Langkah pertama yang dilakukan adalah persiapan bahan. Persiapan bahan yaitu pembobokan limbah beton bekas pengujian, pembelian material agregat dan aspal dan pembelian bahan lain yang dibutuhkan. Setelah itu, material agregat dan aspal tersebut diuji dan harus sesuai dengan spesifikasi. Pada pengujian agregat yang dilakukan adalah uji berat jenis dan penyerapan air, uji abrasi, dan uji kadar lolos saringan No. 200 dan pada pengujian aspal yang dilakukan adalah uji penetrasi, uji berat jenis aspal, uji titik lembek, dan uji viskositas. Gradasi yang digunakan pada adalah gradasi yang ideal, yaitu nilai \% lolos kumulatif adalah nilai tengah dari Spesifikasi Umum lolos kumulatif seperti terlihat pada Tabel 1.

Tabel 1. Gradasi Ideal

\begin{tabular}{cccc}
\hline $\begin{array}{c}\text { Ukuran Ayakan } \\
(\mathbf{m m})\end{array}$ & $\begin{array}{c}\text { Spek Umum } \\
\text { Lolos Kumulatif }\end{array}$ & $\begin{array}{c}\text { \% Lolos } \\
\text { Kumulatif (Ideal) }\end{array}$ & $\begin{array}{c}\text { \% } \\
\text { Tertahan }\end{array}$ \\
\hline 19 & 100 & 100 & 0 \\
\hline 12,5 & $90-100$ & 95 & 5 \\
\hline 9,5 & $77-90$ & 83,5 & 16,5 \\
\hline 4,75 & $53-69$ & 61 & 39 \\
\hline 2,36 & $33-53$ & 43 & 57 \\
\hline 1,18 & $21-40$ & 30,5 & 69,5 \\
\hline 0,6 & $14-30$ & 22 & 78 \\
\hline 0,3 & $9-22$ & 15,5 & 84,5 \\
\hline 0,15 & $6-15$ & 10,5 & 89,5 \\
\hline 0,075 & $4-9$ & 6,5 & 93,5 \\
\hline
\end{tabular}

Untuk mendapatkan nilai yang mendekati kadar aspal optimum digunakan rumus kadar aspal rencana $(\mathrm{Pb})$ di bawah ini.

$$
\mathbf{P b}=\mathbf{0 , 0 3 5}(\% \mathrm{CA})+\mathbf{0 , 0 4 5}(\% \text { FA })+\mathbf{0 , 1 8}(\% \text { Filler })+\mathrm{K}
$$

Di mana:

$\mathrm{Pb} \quad=$ kadar aspal perkiraan

CA = agregat kasar tertahan saringan No. 8

FA = agregat halus lolos saringan No. 8 dan tertahan No. 200

Filler = agregat halus lolos saringan No. 200

Nilai konstanta sekitar 0,5 - 1,0 untuk AC dan HRS.

Perkiraan awal kadar aspal rencana campuran diperlukan agar benda uji yang dibuat tidak banyak. Membuat benda uji dengan kadar aspal menggunakan rumus di atas, dibulatkan menjadi 0,5\%, dengan tiga kadar aspal di atas dan dua kadar aspal di bawah kadar aspal perkiraan awal yang sudah dibulatkan mendekati $0,5 \%$ ini.

$$
\begin{aligned}
\mathrm{Pb} & =0,035(\% \mathrm{CA})+0,045(\% \mathrm{FA})+0,18(\% \mathrm{FF})+\mathrm{K} \\
\% \mathrm{CA} & =57 \% \\
\% \mathrm{FA} & =36,5 \% \\
\% \mathrm{FF} & =6,5 \% \\
\mathrm{~Pb} & =0,035(57 \%)+0,045(36,5 \%)+0,18(6,5 \%)+\mathrm{K} \\
& =4,81+\mathrm{K}(\text { diambil } \mathrm{K}=0,690,5<\mathrm{K}<1) \\
& =5,50 \%
\end{aligned}
$$

Maka kadar aspal yang digunakan adalah $4,5 \% ; 5,0 \% ; 5,5 \% ; 6,0 \% ; 6,5 \%$; dan 7,0\%.

Berat total benda uji yang digunakan adalah 1150 gram dan 2500 gram. Berat substitusi agregat ditentukan berdasarkan masingmasing ukuran ayakan. Perhitungan berat masing-masing agregat terdapat pada Tabel 1. Benda uji yang telah dibuat harus diuji dengan pengujian GMM (Gravity Maximum of Mix) dan Marshall. Pengujian GMM dan Marshall dimaksudkan untuk mengetahui karakteristik campuran. Karakteristik campuran aspal meliputi stabilitas, flow, stabilitas aspal, VIM, VMA, dan VFB. Lalu penentuan kadar aspal optimum dapat dilakukan dengan pendekatan kepadatan mutlak. Setelah itu, dilakukan pengujian indeks perendaman aspal beton sesuai dengan kadar aspal optimum sehingga didapatkan nilai stabilitas sisa setelah benda uji dilakukan perendaman selama 24 jam dibagi dengan nilai stabilitas sisa setelah benda uji dilakukan perendaman selama 30 menit pada suhu $60^{\circ} \mathrm{C}$. 


\section{TINJAUAN PUSTAKA}

\subsection{Campuran Beraspal Panas dengan Gradasi Rapat}

Bahan penyusun campuran Asphalt Concrete-Wearing Course (AC-WC) adalah sebagai berikut.

\section{a. Agregat Kasar}

Fraksi agregat kasar untuk campuran adalah yang tertahan No. $4(4,75 \mathrm{~mm})$ terdiri dari dari batu pecah atau kerikil pecah yang bersih, keras, awet dan bebas dari bahan lain yang mengganggu seperti lempung. Agregat kasar harus mempunyai angularitas dan harus memenuhi spesifikasi. Agregat yang digunakan harus dari sumber dan jenis yang sama untuk menjamin keseragaman campuran. (Kementrian Pekerjaan Umum, 2010).

\section{b. Agregat Halus}

Agregat halus dari sumber mana pun harus terdiri dari pasir atau pengayakan batu pecah yang lolos ayakan No. 4 (4,75 mm). Agregat halus yang digunakan untuk campuran aspal harus bersih, keras, dan bebas dari gumpalan-gumpalan lempung dan bahan-bahan lain yang dapat mengganggu. Agregat halus dapat digunakan dalam campuran AC sampat suatu batas tidak melampau $15 \%$ terhadap berat total campuran. (Kementrian Pekerjaan Umum, 2010).

\section{c. Bahan pengisi (Filler)}

Campuran beraspal harus mengandung bahan pengisi minimal $1 \%$ dan maksimal $2 \%$ terhadap berat total agregat. Bahan pengisi yang digunakan pada penelitian ini adalah semen. (Kementrian Pekerjaan Umum, 2010)

Adapun tujuan dari aspal modifikasi menurut (POLSRI, 2011) adalah sebagai berikut.

1. Sifat-sifat aspal alami yang kurang tahan terhadap keadaan iklim sekitar yang sering membuat aspal lembap dan mudah rusak

2. Aspal pada temperatur rendah tidak rapuh/getas sehingga mengurangi potensi terjadinya retak (cracking).

3. Tidak tahan terhadap genangan air sehingga memerlukan drainase yang baik untuk mempercepat proses pengurangan jumlah genangan di aspal.

4. Mencari sifat aspal yang baru, contohnya aspal yang fleksibel (untuk jalan-jalan yang memiliki tanah yang labil dan selalu bergerak)

5. Aspal pada temperatur tinggi lebih stabil sehingga potensi terjadinya alur (rutting) pada perkerasan beraspal dapat dikurangi.

6. Mengurangi viskositas pada temperatur penghamparan sehingga dicapai kemudahan pelaksanaan penghamparan sekaligus pemadatannya.

7. Meningkatkan stabilitas dan kekuatan campuran beraspal.

\subsection{Limbah Beton}

Limbah beton adalah material sisa beton yang sudah tidak layak dipakai lagi untuk konstruksi. Limbah beton yang digunakan dalam penelitian ini adalah limbah beton hasil pengujian praktik di POLBAN banyak yang tidak terpakai dan hanya menjadi sampah sehingga menghabiskan lahan, oleh karena itu makan dilakukan substitusi limbah beton untuk campuran aspal AC-WC.

\section{HASIL DAN PEMBAHASAN}

\subsection{Hasil Pengujian Mutu Aspal}

Hasil pengujian mutu aspal dapat dilihat pada Tabel 2.

Tabel 2. Hasil Pengujian Mutu Aspal

\begin{tabular}{|c|c|c|c|c|}
\hline No & Jenis Pengujian & Hasil & Standar Uji: Spesifikasi & Ket \\
\hline 1 & Penetrasi Aspal & 55,95 & $\begin{array}{l}\text { SNI 06-2456-1991: } \\
\text { Pen } 40(40-59)\end{array}$ & Sesuai \\
\hline 2 & Berat Jenis Aspal & 1,04 & $\begin{array}{l}\text { SNI 06-2488-1991: } \\
\geq 1 \text { untuk Pen } 40\end{array}$ & Sesuai \\
\hline 3 & Titik Lembek Aspal & $50,81^{\circ} \mathrm{C}$ & $\begin{array}{l}\text { SNI 06-2434-1991: } \\
\text { Pen } 40\left(51-63^{\circ} \mathrm{C}\right)\end{array}$ & Sesuai \\
\hline 4 & Viskostitas & $\begin{array}{l}125,88^{\circ} \mathrm{C} \\
117,17^{\circ} \mathrm{C}\end{array}$ & - & - \\
\hline
\end{tabular}




\subsection{Hasil Pengujian Mutu Agregat}

Hasil pengujian agregat dapat dilihat pada Tabel 3.

Tabel 3. Hasil Pengujian Mutu Agregat

\begin{tabular}{|c|c|c|c|c|c|c|c|}
\hline No & Jenis Pengujian & Spl. & Scr. & Ab.Bt. & Fill & $\begin{array}{l}\text { Standar Uji: } \\
\text { Spesifikasi }\end{array}$ & Ket \\
\hline \multirow[t]{6}{*}{1} & Berat Jenis SSD & 2,57 & 2,56 & 2,5 & & \multirow{6}{*}{$\begin{array}{l}\text { SNI 03-1969-1990 } \\
\text { (Agregat Kasar): } \\
\text { Peny. Air: } \leq 3 \% \\
\text { SNI 03-1970-1990 } \\
\text { (Agregat Halus): } \\
\text { Peny. Air: } \leq 10 \% \\
\text { SNI 15-2049-2004 } \\
\text { (Semen): } \\
\text { 3,00 - 3,20 }\end{array}$} & \multirow[t]{4}{*}{-} \\
\hline & Berat Jenis Kering Oven & 2,48 & 2,47 & 2,36 & & & \\
\hline & & & & & & & \\
\hline & Berat Jenis Semu & 2,72 & 2,73 & 2,76 & & & \\
\hline & Berat Jenis Semen & & & & \multirow[t]{2}{*}{3,01} & & Sesuai \\
\hline & Penyerapan Air & 0,4 & 0,41 & 0,62 & & & Sesuai \\
\hline \multirow[t]{2}{*}{2} & \multirow[b]{2}{*}{500 put } & 5,64 & & & & $\begin{array}{l}\text { SNI } 2417: 2008: \\
\leq 6 \%\end{array}$ & Sesuai \\
\hline & & $\begin{array}{c}28,0 \\
9\end{array}$ & & & & $\begin{array}{c}\text { SNI } 2417: 2008: \\
\leq 30 \%\end{array}$ & Sesuai \\
\hline 3 & $\begin{array}{l}\text { Kadar Lolos Ayakan No. } \\
200\end{array}$ & 0,56 & 3,07 & 4,7 & & $\begin{array}{l}\text { SNI 03-4142-1996: } \\
\leq 2 \% \text { (agr. kasar) } \\
\leq 10 \% \text { (agr. halus) }\end{array}$ & $\begin{array}{l}\text { Untuk split dan abu batu sesuai } \\
\text { dengan spek, sedangkan screen } \\
\text { tidak sesuai (harus dilakukan } \\
\text { pencucian sebelum digunakan) }\end{array}$ \\
\hline
\end{tabular}

(Spesifikasi Umum Binamarga Tahun 2010 Revisi 3)

\subsection{Karakteristik Campuran Aspal dengan Substitusi Limbah Beton Sebagai Agregat Kasar}

Pengujian GMM dan Marshall dimaksudkan untuk mengetahui karakteristik campuran. Karakteristik campuran aspal meliputi stabilitas, flow, stabilitas aspal, VIM, VMA, dan VFB. Berdasarkan pengujian yang telah dilakukan pada Kadar Aspal Optimum didapatkan hasil seperti pada Tabel 8.

Tabel 8. Hasil Pengujian Benda Uji

\begin{tabular}{ccccc}
\hline Karakteristik & Spesifikasi & \multicolumn{3}{c}{ Pada Kadar Aspal Optimum } \\
& & 0 \% Limbah & 50 \% Limbah & 100 \% Limbah \\
\hline Stabilitas & min. 800 kg & $1182,6 \mathrm{~kg}$ & $1448,2 \mathrm{~kg}$ & $1453,2 \mathrm{~kg}$ \\
\hline Flow & $2-4 \mathrm{~mm}$ & $3,94 \mathrm{~mm}$ & $2,15 \mathrm{~mm}$ & $2,08 \mathrm{~mm}$ \\
\hline Stabilitas Sisa & $\min 90 \%$ & $106 \%$ & $94 \%$ & $74 \%$ \\
\hline VIM & $3-5 \%$ & $4,21 \%$ & $4,94 \%$ & $6,58 \%$ \\
\hline VMA & min. 15\% & $15,54 \%$ & $15,83 \%$ & $16,95 \%$ \\
\hline VFB & min 65 \% & $89,07 \%$ & $88,27 \%$ & $87,21 \%$ \\
\hline \multicolumn{5}{c}{ (Spesifikasi Umum Binamarga Tahun 2010 Revisi 3) }
\end{tabular}




\section{a. Stabilitas}

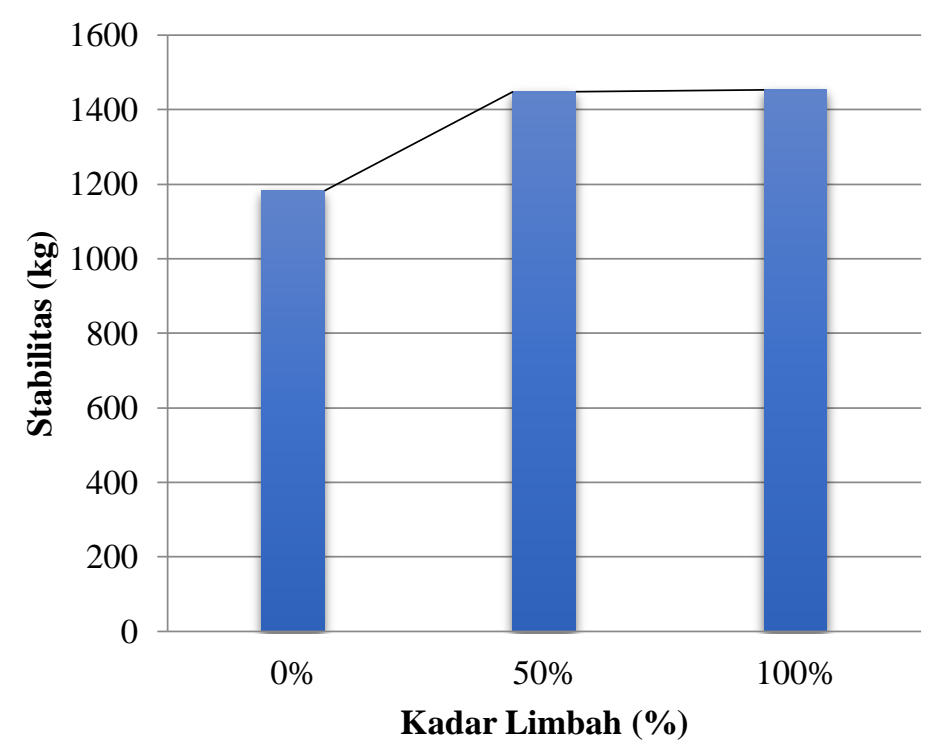

Gambar 2. Grafik Pengaruh Limbah Beton Terhadap Nilai Stabilitas

Semakin tinggi kadar limbah beton yang digunakan maka semakin tinggi nilai stabilitas campuran tersebut, seperti yang ditunjukkan grafik hubungan antara kadar limbah dan nilai stabilitas pada Gambar 2. Dengan kadar limbah 50\% nilai stabilitas naik sebesar $18,34 \%$, sedangkan dengan kadar limbah $100 \%$ nilai stabilitas naik sebesar 18,62\%. Sesuai dengan penelitian sebelumnya, nilai stabilitas cenderung bertambah pada kadar limbah beton yang lebih besar (Andhikatama, 2013 ).

\section{b. Flow}

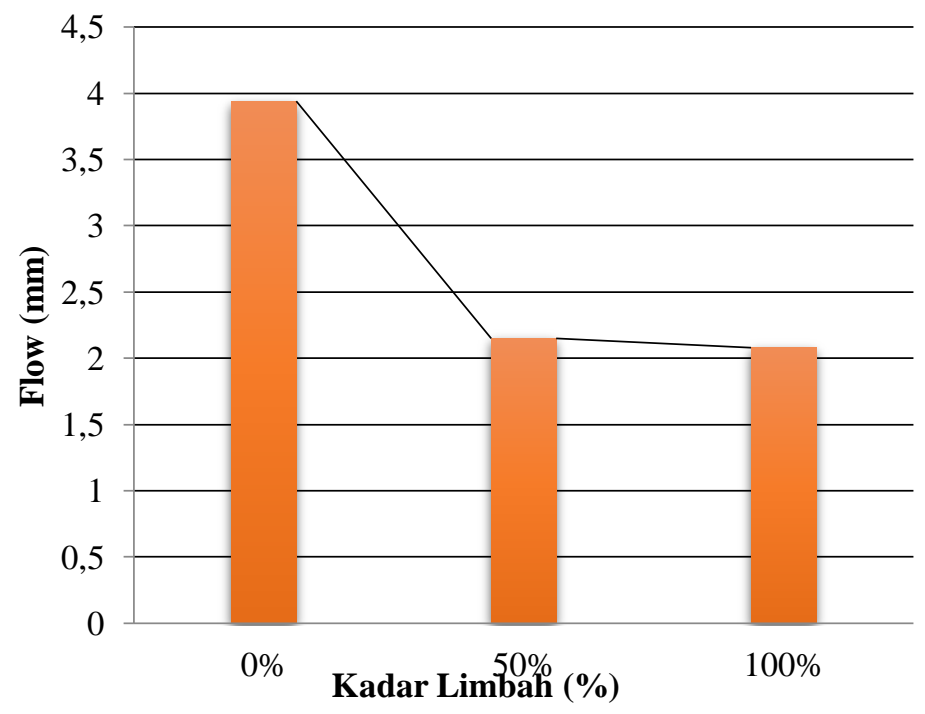

Gambar 3. Grafik Pengaruh Limbah Beton Terhadap Nilai Flow

Semakin tinggi kadar limbah beton yang digunakan maka semakin kecil nilai flow campuran tersebut, seperti yang ditunjukkan grafik hubungan antara kadar limbah dan nilai flow pada Gambar 3. Dengan kadar limbah 50\% nilai flow turun sebesar 45,43\%, sedangkan dengan kadar limbah $100 \%$ nilai flow turun sebesar 47,21\%. Sesuai dengan penelitian sebelumnya, nilai flow cenderung mengalami penurunan pada variasi kadar limbah beton yang lebih besar dikarenakan aspal yang diserap agregat limbah beton lebih banyak daripada kondisi campuran normal (Andhikatama, 2013 ). 
Vol. 22, No. 1, Maret 2020

c. VIM (Voids in Mix)

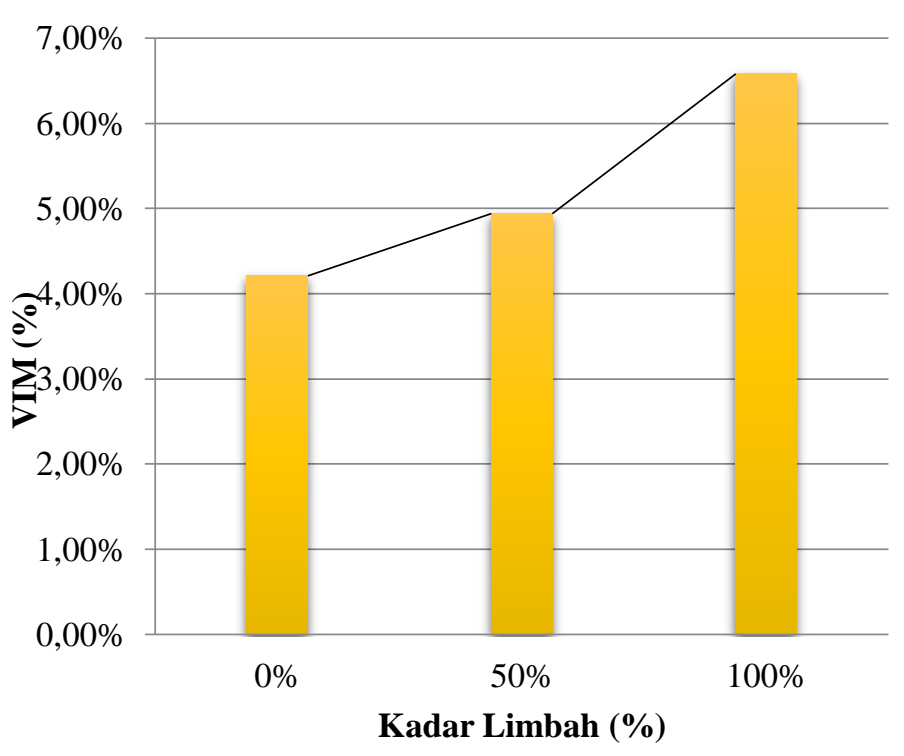

Gambar 4. Grafik Pengaruh Limbah Beton Terhadap Nilai VIM

Semakin tinggi kadar limbah beton yang digunakan maka semakin tinggi nilai VIM campuran tersebut, seperti yang ditunjukan grafik hubungan antara kadar limbah dan nilai VIM pada Gambar 4. Dengan kadar limbah 50\% nilai VIM naik sebesar 14,78\%, sedangkan dengan kadar limbah $100 \%$ nilai VIM naik sebesar 36,02\%. Pada penelitian ini, campuran dengan kadar limbah beton $100 \%$ tidak memenuhi spesifikasi. Sesuai dengan dengan penelitian sebelumnya, terdapat nilai VIM yang tidak memenuhi spesifikasi dikarenakan limbah beton menyebabkan banyaknya rongga pada campuran (Andhikatama, 2013 ).

d. VMA (Voids in Mineral Aggregate)

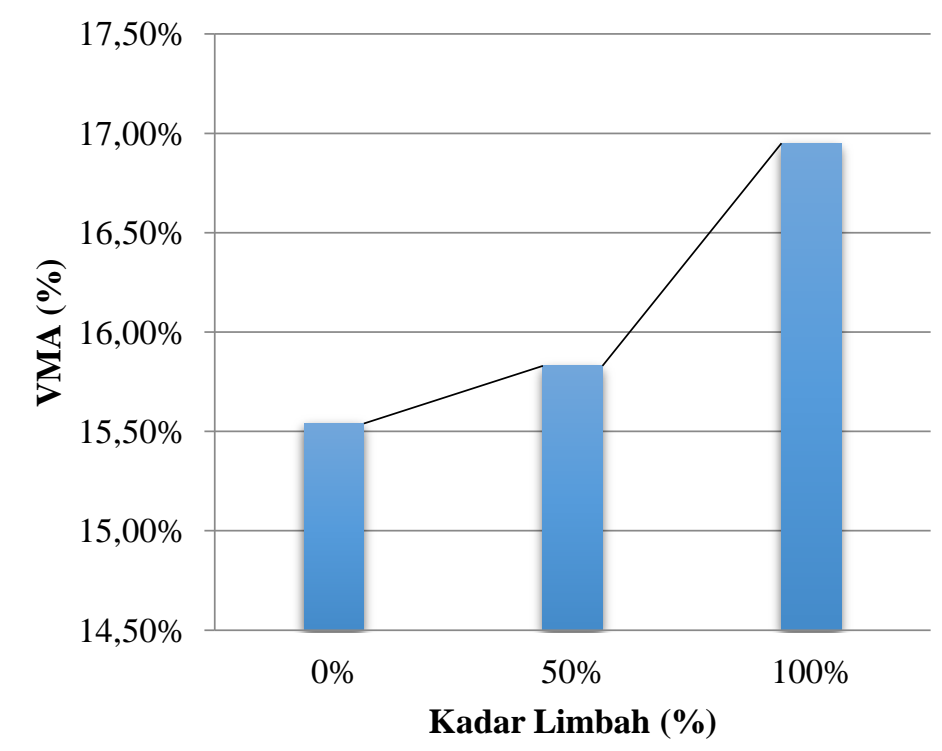

Gambar 5. Grafik Pengaruh Limbah Beton Terhadap Nilai VMA

Semakin tinggi kadar limbah beton yang digunakan maka semakin tinggi nilai stabilitas campuran tersebut, seperti yang ditunjukkan grafik hubungan antara kadar limbah dan nilai VMA pada Gambar 5. Dengan kadar limbah 50\% nilai VMA naik sebesar 18,26\%, sedangkan dengan kadar limbah $100 \%$ nilai VMA naik sebesar 23,66\%. Sesuai dengan penelitian sebelumnya, nilai VMA cenderung semakin bertambah pada kadar limbah beton yang lebih besar dikarenakan agregat limbah beton memiliki nilai penyerapan lebih besar (Andhikatama, 2013 ). 
Vol. 22, No. 1, Maret 2020

e. VFB (Voids Filled Bitumen)

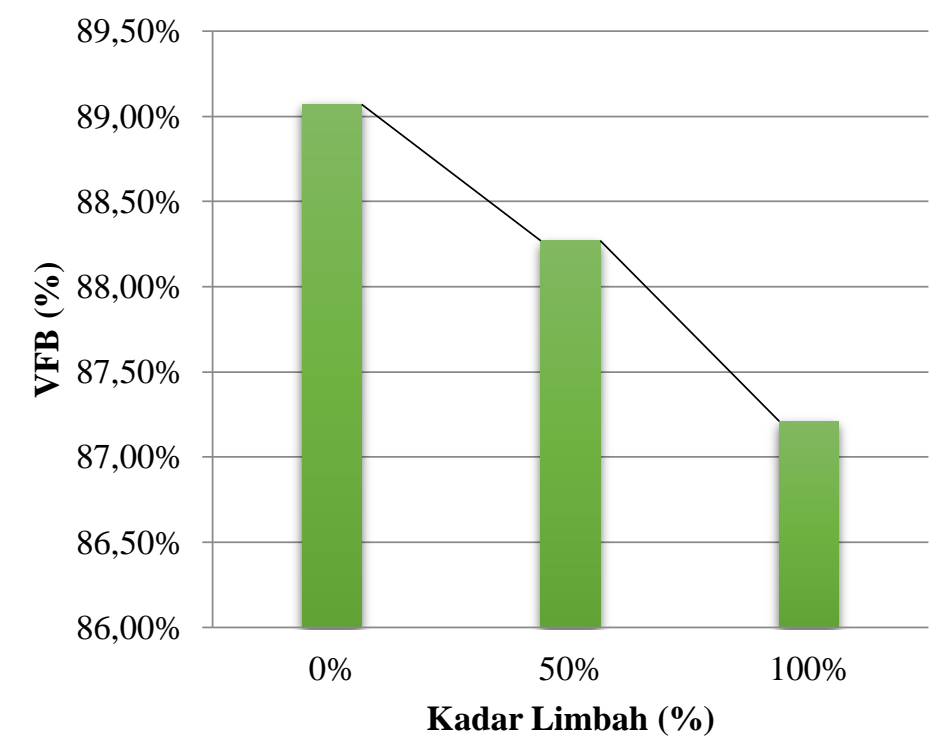

Gambar 6. Grafik Pengaruh Limbah Beton Terhadap Nilai VFB

Semakin tinggi kadar limbah beton yang digunakan maka semakin kecil nilai VFB campuran tersebut, seperti yang ditunjukkan grafik hubungan antara kadar limbah dan nilai VFB pada Gambar 6. Dengan kadar limbah 50\% nilai VFB turun sebesar 0,90\%, sedangkan dengan kadar limbah $100 \%$ nilai VFB turun sebesar 0,90\%. Sesuai dengan penelitian sebelumnya, semakin besar kadar limbah beton yang digunakan maka semakin kecil nilai VFB dikarenakan aspal yang seharusnya mengisi rongga terabsorpsi oleh agregat limbah beton yang memiliki nilai penyerapan lebih besar (Andhikatama, 2013 ).

\section{f. Stabilitas Sisa}

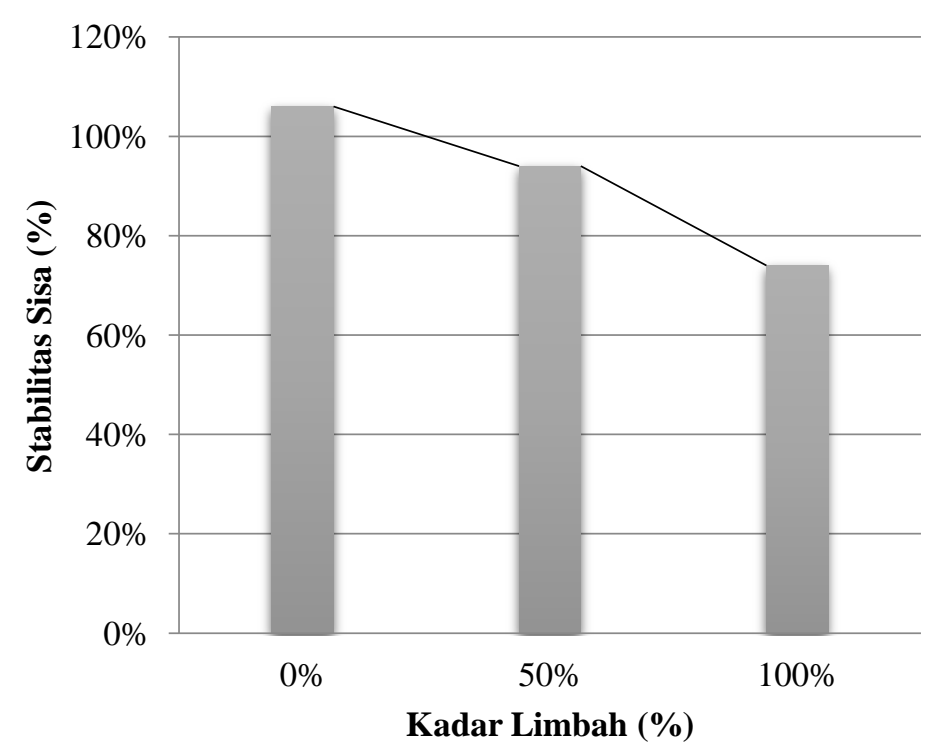

Gambar 7. Grafik Pengaruh Limbah Beton Terhadap Nilai Stabilitas Sisa

Semakin tinggi kadar limbah beton yang digunakan maka semakin kecil nilai stabilitas sisa campuran tersebut, seperti yang ditunjukkan grafik hubungan antara kadar limbah dan nilai stabilitas sisa pada Gambar 7. Dengan kadar limbah 50\% nilai stabilitas sisa turun sebesar 20,75\%, sedangkan dengan kadar limbah 100\% nilai stabilitas sisa turun sebesar 30,19\%. 
Dapat dilihat dari grafik hubungan antara kadar limbah dengan karakteristik aspal bahwa nilai stabilitas meningkat. Namun, VFB menurun ketika kadar limbah semakin tinggi. Hal tersebut terjadi karena dengan adanya limbah pada campuran menyebabkan banyaknya rongga yang tidak terisi aspal. Rongga yang tidak terisi aspal menyebabkan banyaknya air yang masuk ke dalam rongga dan penyerapan air yang tinggi oleh limbah saat dilakukan perendaman. Banyaknya air yang terserap menyebabkan campuran aspal mudah hancur saat dilakukan pembebanan sehingga nilai stabilitas sisa menurun.

\section{KESIMPULAN}

Adapun kesimpulan dari penelitian ini adalah sebagai berikut.

a. Penggunaan limbah beton sebagai pengganti agregat kasar pada campuran aspal AC-WC mempengaruhi karakteristik aspal. Pada kadar limbah beton 50\% karakteristik aspal yang meningkat yaitu nilai stabilitas 18,34\%, VIM 14,78\%, dan VMA $18,26 \%$. Sedangkan pada kadar 100\% karakteristik aspal yang meningkat yaitu nilai stabilitas 18,62\%, VIM 36,02\%, dan VMA $23,66 \%$.

b. Karakteristik aspal harus memenuhi persyaratan pada Spesifikasi Umum Bina Marga 2010 Revisi 3. Sesuai pada Tabel 8., pada penggunaan kadar limbah beton $100 \%$ terdapat salah satu syarat karakteristik aspal yang tidak terpenuhi yaitu VIM. Sedangkan pada kadar limbah beton 50\%, memenuhi semua spesifikasi karakteristik aspal. Oleh karena itu, kadar limbah beton optimum yang dapat digunakan sebagai substitusi agregat kasar pada campuran aspal AC-WC yaitu pada kadar limbah beton $50 \%$.

\section{SARAN}

Dalam pelaksanaan penelitian selanjutnya mengenai limbah beton ini dapat dilakukan dengan variasi mutu limbah beton dan lebih banyak variasi kadar limbah beton. Selain itu, dapat direalisasikan untuk mengetahui kinerja campuran aspal tersebut secara langsung di lapangan.

\section{DAFTAR PUSTAKA}

[1] Amaliah. (2019). Laporan Praktikum Laboratorium Uji Bahan.

[2] Andhikatama. (2013 ). Pemanfaatan Limbah Beton Sebagai Pengganti Agregat Kasar pada Campuran AC-WC Gradasi Kasar.

[3] Kementrian Pekerjaan Umum. (2010). Spesifikasi Umum Bina Marga Revisi 3 Divisi 6 Perkerasan Aspal.

[4] POLSRI. (2011). Diambil kembali dari eprints.polsri.ac.id: http://eprints.polsri.ac.id/893/3/ BAB\%20II\%20TINJAUAN\%20PUSTAKA.pdf

[5] Rahmad. (2016). Pemanfaatan Limbah Beton pada Campuran Hot Rolled Sheet Base Ditinjau dari Aspek Marshall.

[6] Rahman. (2014). Kajian Pemanfaatan Limbah Beton Sebagai Material CTB. 